\title{
Oral Health of Children of Migrant Farm Workers in Northwest Michigan
}

\author{
Marilyn Woolfolk, DDS, MPH \\ Margot Hamard, DDS, MPH \\ Robert A. Bagramian, DDS, DrPH \\ Department of Community Dentistry \\ School of Dentistry \\ The University of Michigan \\ Ann Arbor, MI 48109
}

\begin{abstract}
.
A considerable number of Hispanic agricultural workers come to Northwest Michigan during the summer every year to harvest fruit and vegetable crops. The Department of Community Dentistry of The University of Michigan School of Dentistry helps provide dental services for these migrant workers and their families. Some 203 five-to14-year-old children of migrant farm workers were examined for caries and periodontal condition and the results compared with recent national surveys. Traditional indicators of dental caries experience (DMFT/dft and DMFS/dfs indices), periodontal disease (PI), and oral cleanliness (OHI-S) were used by one examiner. These migrant children presented higher numbers of decayed teeth and lower numbers of restored teeth than United States schoolchildren generally. Migrant children also presented less caries-free teeth and higher $\mathrm{PI}$ and $\mathrm{OHI}-\mathrm{S}$ scores than United States children generally.
\end{abstract}

Introduction

Members of the migrant labor force have been characterized as a medically underserved population, mainly because their high degree of mobility impedes access to medical care (1). A similar plight has been described for migrants with regard to dental services (2). Accounts of organized attempts to address the dental needs of members of the migrant population include descriptions of programs in Colorado $(3,4)$, Connecticut $(5,6)$, Iowa (7), Wisconsin $(8,9)$, Michigan $(10,11)$, and various other states (12-14). These programs focused on provision of dental health education and of dental care for children and adults. Efforts to plan and provide optimal dental services for migrants have been beset by such difficulties as overcoming language barriers (15), understanding cultural influences that affect health practices $(3,15)$, and coping with relatively short stays at specific locations before recommended treatment or follow-up can be accomplished $(3,5)$.

A few dental health surveys have been accomplished by various investigators $(5,6,16,17)$ to assess the oral health of migrant groups. This body of literature relative to the dental health status of
Harold Sgan-Cohen, DDS, MPH

Department of Community Dentistry

Hebrew University-Hadassah School of Dental Medicine Jerusalem, Israe

migrants suggests that the adequacy of treatment level for migrants of varying ethnic backgrounds in the United States still leaves much to be desired. Because of their transitory lifestyle, the responsibility for migrant workers' dental care may be passed from area to area and from state to state. This situation is compounded by the documented lack of preventive dental health behavior among migrants (18).

Comparisons have been made between the dental health of migrant children and that of urban children where it was noted that migrant children had a low prevalence of restorations and a high rate of caries activity (16). The dental health of a group of migrant children in Hartford, Connecticut was evaluated in 1978 where it was determined that they demonstrated a high caries attack rate relative to a group of indigenous Connecticut children (5). Since the results of that survey were reported, the literature has been void of further evaluations of dental health status of migrants. More current assessments of the dental health of migrant groups would seem to be indicated because the oral health of migrants may have improved in recent years.

\section{“...the dental health needs of this highly mobile population are not being met adequately and should receive greater attention."}

The present paper reports the results of a dental health survey of a group of migrant children in Michigan completed in 1982. The purpose of gathering these data was to assess the prevalence of dental caries and periodontal disease among these children who are primarily of Mexican-American descent, and to determine the extent to which dental health needs are being met for their highly mobile population. Data presented here highlight the dental treatment needs of this selected population and contrast their dental health status with that of children of similar ages from recent national surveys.

\section{Materials and Methods}

Migrant families come yearly to help harvest the crops in the Traverse City area of Northwest Lower 
Michigan. The study population consisted of 203 children from these families who were attending migrant schools in that vicinity. These children, primarily of Mexican-American descent, aged 5-14 years, come into Michigan primarily from Texas and Florida according to their school records. The children were examined while seated in portable dental chairs by one examiner (H.S.) and the teeth were inspected using a dental mouth mirror and a No. 5 explorer under illumination provided by portable Dentalite \#304 (Good-Lite Co.). To assess caries experience, the DMF index (19) and the def index (20) were used. The numbers of decayed, missing, and filled teeth (DMFT) and surfaces (DMFS) were recorded for the permanent dentition as were the numbers of decayed and filled teeth (dft) and surfaces (dfs) in the primary dentition. Periodontal disease was measured with the Periodontal Index (PI) of Russell (21). Oral hygiene status was determined by the Simplified Oral Hygiene Index (OHI-S) of Greene and Vermillion (22). Intra-examiner variability could not be tested during the examination because those children needing treatment received it immediately after the examination. Radiographs were not exposed. Differences between the mean scores for males and females were tested utilizing the Student's t-test at the five percent level of significance.

\section{Results}

Caries

On the basis of dental examinations, 89 boys and 114 girls, aged five to 14 years old, averaged 2.2 DMF teeth for both sexes, with a mean 1.5 decayed,
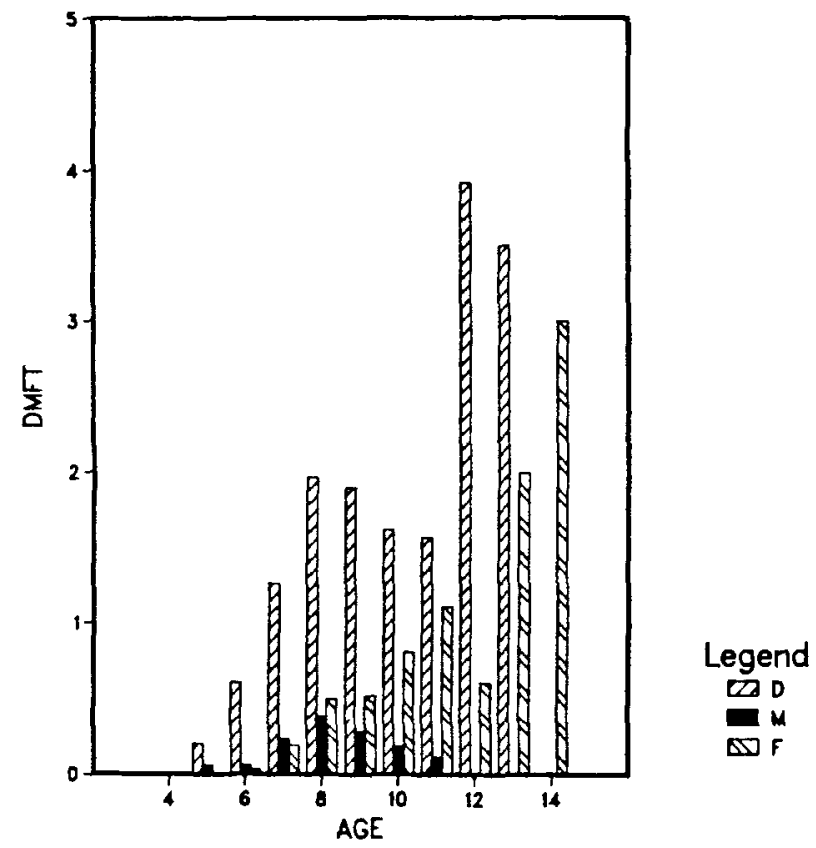

FIGURE 1. Distribution of components of D, M, and $\mathrm{F}$ teeth for Michigan migrant children.
0.1 missing, and 0.5 filled teeth. The mean number of DMFT increased slowly but steadily with age. There were few missing teeth (Figure 1). The mean number of DMFT for girls was 2.3, whereas that for boys was 2.2 , but the differences between the means were not statistically significant $(\mathrm{P}=0.86)$.

The mean DMFS value for all children was 2.9 . The mean DMFS for males was 2.7, and 3.1 for females. DMFT and DMFS mean values for all children were about the same, and represented primarily single-surface carious lesions or restorations in permanent teeth.

The mean dft values for both sexes was 2.9 , with a mean of 2.3 decayed and 0.5 filled primary teeth. The mean number of $\mathrm{df}$ teeth declined with advancing age (Figure 2). Boys and girls had about the same mean number of $\mathrm{df}$ teeth. There was relatively little variation by sex in the overall mean number of any $\mathrm{df}$ component. Differences between the mean $\mathrm{dft}$ for males and females were not statistically significant $(P=0.63)$.
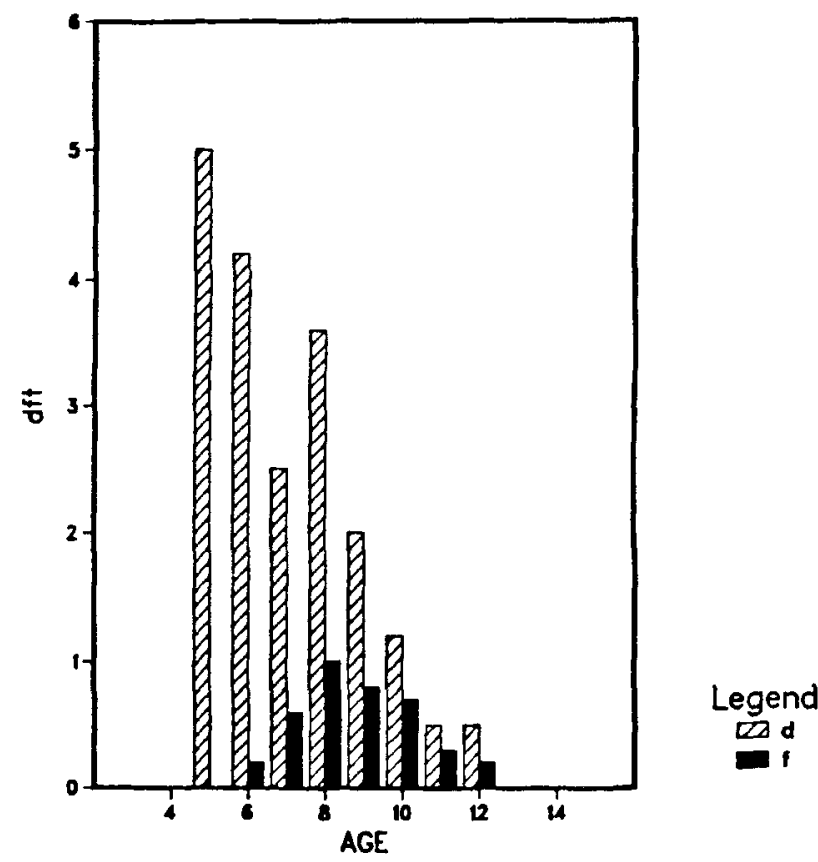

FIGURE 2. Distribution of components of $d$ and $f$ teeth for Michigan migrant children.

The mean $\mathrm{dfs}$ value for all children was 4.8 . The mean dfs value for males was 4.7 , and 4.8 for females. The differences between the means were not statistically significant. The mean $\mathrm{dfs}$ value was about two times the mean dft value for all children.

Fifty-four percent of the children had at least one decayed first molar, and 10 percent of the children had all four first permanent molars decayed.

Approximately 37 percent of the children exhibited a caries-free permanent dentition and approximately 14 percent were found to be caries-free in both the primary and permanent dentition. 


\section{TABLE 1}

Mean Debris, Calculus, OHI-S and PI values, by age for boys and girls aged 5-14, Migrant Program, Michigan, 1982.

\begin{tabular}{lrllll}
\hline Age & $\mathbf{n}$ & Debris & Calculus & OHI-S & PI \\
\hline 5 & 15 & 1.07 & 0.11 & 1.18 & 0.20 \\
6 & 15 & 1.07 & 0.00 & 0.90 & 0.15 \\
7 & 31 & 0.92 & 0.00 & 0.90 & 0.14 \\
8 & 34 & 0.93 & 0.01 & 0.95 & 0.14 \\
9 & 21 & 1.00 & 0.01 & 0.91 & 0.18 \\
10 & 32 & 0.91 & 0.01 & 0.91 & 0.18 \\
11 & 26 & 0.77 & 0.07 & 0.85 & 0.21 \\
12 & 13 & 0.94 & 0.06 & 1.01 & 0.26 \\
13 & 4 & 0.79 & 0.12 & 0.91 & 0.38 \\
14 & 1 & 0.66 & 0.33 & 1.00 & 0.00 \\
All Ages & 203 & 0.91 & 0.03 & 0.95 & 0.18
\end{tabular}

\section{Periodontal Disease}

The mean PI value for all children in the present study was 0.18 (Table 1 ). The mean PI value for males was 0.19 and 0.18 for females. These means were not significantly different. After age six, the mean PI values increased slowly but steadily with age. The maximum PI value was 1.34.

The mean OHI-S score for all children was 0.95 (Table 1). The average OHI-S score for males was 1.01 and the value for females was 0.89 . Differences between the mean OHI-S scores for males and females were not statistically significant. There was no consistent trend in the mean $\mathrm{OHI}-\mathrm{S}$ scores as age increased. The debris component was 0.91 and the calculus component was 0.03 . The debris component accounted for 95.8 percent of the total oral hygiene score. The maximum OHI-S value was 2.5 .

\section{Discussion}

Comparability with other studies is always limited by differences in study design and analytic methods. Nevertheless, some comparisons of these results with those of selected national surveys $(23,24)$ will be made. To facilitate these comparisons, the present sample was divided into the following subgroups: children 6-11 years, children 5-14 years, and children 5-11 years. Children 6-11 years were compared to similarly aged subjects from the 1971-74 National Center for Health Statistics (NCHS) Survey (23). Five to 14-year-olds and 5-11-year-olds were compared to similar age groups from the 1979-80 National Dental Caries Prevalence Survey (24).

Some indication of the differences in the level of dental care among children may be obtained from examination of the proportion of total DMFS or DMFT scores attributed to decayed, missing, and filled surfaces or teeth, respectively. Figure 3 represents the distribution and comparison of DMFT components for the NCHS survey (23) and Michigan Migrant study for the ages six to 11 years old. The major differences between DMFT findings in this study and the NCHS survey were the per- centages of decayed and filled teeth. Although there were not many missing teeth in the present group of migrant children, the large number of decayed teeth could become missing in the future if treatment is not provided.

\section{NCHS 1971-74}

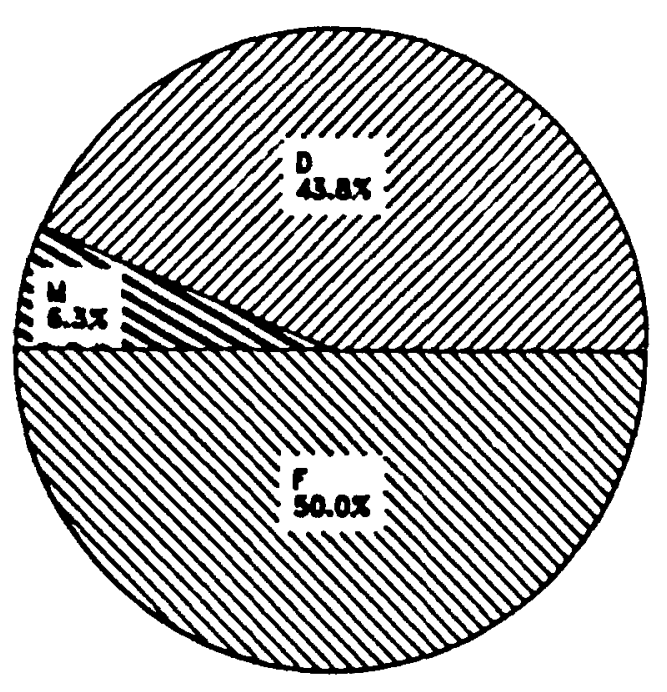

\section{MICHIGAN MIGRANT 1982}

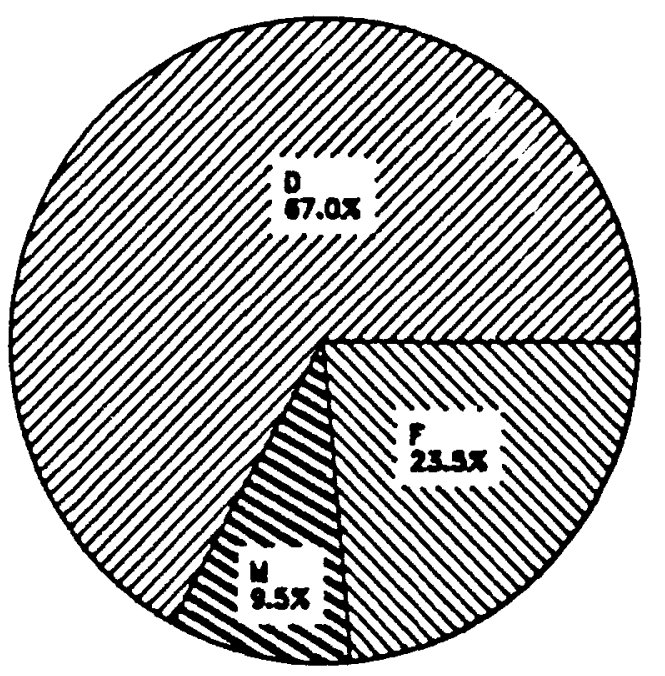

FIGURE 3. Percentage of D, M, F teeth for United States children (National Center for Health Statistics, 1971-74) and Michigan migrant children (1982). (Ages six to 11)

When data describing only children aged 5-14 from the National Dental Caries Prevalence Survey (24) were compared, DMFS values for United States children were consistently lower than the same values for migrant children of the same age in the present study (Figure 4). The percentage of teeth with decayed surfaces for migrant children was 
65.18 versus 16.8 percent for United States schoolchildren. The percentage of teeth with filled surfaces was 29.07 for migrant children compared with 76 percent for United States schoolchildren.

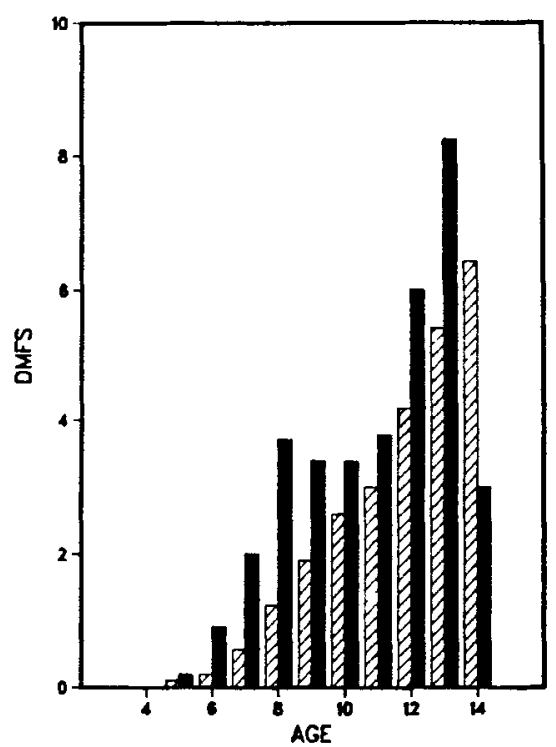

D NJOR 1979-80 Michigan Migrant

FIGURE 4. Distribution of DMFS for United States children (NIDR 1979-80) and Michigan migrant children (1982). (Ages five to 14)

Less than 25 percent of migrant children (5-11 years) had caries-free permanent teeth, while over 58 percent of United States children (5-11 years) had caries-free permanent teeth as reported by Brunelle and Carlos (25) from National Dental Caries Prevalence Survey data. It is important to note that most of the children in the youngest age groups had few permanent teeth. The migrants from the Southwest presumably benefit from exposure to naturally fluoridated water supplies, which may explain the paradoxically high percentage ( 37 percent) of caries-free children (5-14 years). Those migrant children in the study who may not have lived in a naturally fluoridated area, however, would not share that advantage.

TABLE 2

\section{Mean OHI-S and Components and PI Scores for Children Aged 6-11.}

\begin{tabular}{lcc}
\hline INDEX & NCHS & $\begin{array}{c}\text { MICHIGAN } \\
\text { MIGRANT } \\
\text { SCORES }\end{array}$ \\
\hline & $\mathbf{1 9 7 1 - 7 4}$ & \\
Debris & 0.72 & 0.90 \\
Calculus & 0.03 & 0.01 \\
OHI-S & 0.75 & 0.91 \\
PI & 0.11 & 0.17
\end{tabular}

Table 2 shows mean scores for oral debris, calculus, oral hygiene, and periodontal disease for migrant children aged 6-11 compared with the same values for NCHS survey (23). The mean OHI-S value of 0.91 for the subsample of migrant children aged 6-11 was higher than the value of 0.75 for United States children. Gingivitis is prevalent in this migrant population probably as a consequence of oral hygiene neglect. The high oral debris component reflects poor oral cleanliness. Many of the children, when questioned, denied even owning a toothbrush, which would make it difficult to practice good dental hygiene.

The migrant children observed in this study seemed to have a definable dental problem. Although they did not present teeth with extensive disintegration of the crown, a high number of missing teeth, nor advanced periodontal disease; there was a high percentage of decayed teeth, a low percentage of filled teeth, and indications of neglected oral hygiene. Despite any presumed advantage from exposure to naturally fluoridated water that some migrants, particularly those from Texas might enjoy, there remains a high proportion of untreated carious surfaces among the study group as a whole.

By virtue of their high degree of mobility, migrant families are not well-integrated into the traditional dental care system which helps explain their need for treatment. It has been reported that low family income and educational levels depress Hispanics' use of dentists (2). There are no formal data available on the provision and utilization of dental services for this study group. From verbal communication with parents of the children, however, it was learned that aside from isolated instances of emergency service, relatively few children received dental treatment elsewhere with regularity. This pattern would help explain the high percentage of decayed teeth and the rather low level of restorative care among the group.

Besides their lack of resources and characteristic mobility, studies of health agencies suggest that Mexican-Americans often avoid using available health clinics because of cultural conflicts in the definitions of health, causes of disease, and means of treating disease (26). If such avoidance carries over into the dental arena, the predictable result would be infrequent visits to the dentist, poor continuity of care, and less opportunity to initiate preventive procedures or to detect caries in the early stages.

A basic lack of dental health awareness among migrant groups may also affect the level of dental disease in this population. It is likely that members of the population have not been exposed to correct information about fluorides, proper diet, oral hygiene methods and the benefits of good professional dental care. They may not be motivated to seek available dental services because they are unaware of their importance. As a result, their dental health is largely left unattended.

Various circumstances combine to deny many migrants the opportunity to obtain and maintain 
optimal oral health. Given the high percentage of decayed teeth and the indications of poor oral hygiene, it would appear that the dental health needs for this highly mobile population are not adequately being met. The substantial gap between the percentage of filled surfaces of this group of migrant children and that of similarly aged children from national surveys is unsettling. Strategies to close this gap should be developed. Targeting more dental health programs for migrants, reducing the barriers that might discourage utilization of dental services, and intensifying efforts to disseminate oral health information to them should help improve the oral health status of this population group.

\section{Conclusion}

Given the high percentage of decayed teeth, the low level of restorative care, and the indications of oral hygiene neglect, it appears that the dental health needs of this highly mobile population are not being met adequately and should receive greater attention.

\section{References}

1. Bleiweis PR, Reynolds RC, Cohen LD, Butler NA. Health care characteristics of migrant agricultural workers in three Northern Florida counties. J Community Health 1977;3:32-43.

2. Andersen R, Lewis SZ, Giachello AL, Adlay LA, Chiv G. Access to medical care among the Hispanic population of the Southwestern United States. I Health Soc Behav 1981;22:78-89.

3. Downs RA, Bonnet LJ. Colorado dental migrant project. J Colo Dent Assoc 1965;43:17-9.

4. Barnett SE, Call RL. A student community dental experience with migrant farmworkers families and the rural poor. Am J Pub Health 1979;69:1107-13.

5. Cipes MH, Castaldi CR. Dental health of children of migrant farmworkers in Hartford Connecticut. J Conn State Dent Assoc 1982;56:59-62.

6. Ragno J, Castaldi CR. Dental health in a group of migrant children in Connecticut. J Conn State Dent Assoc 1982;56:15-21.

7. Sierk D. lowa students care for migrant farmworkers. Dent Stud 1971;50:60-1
8. Sharma PS. Because it needs to be done. J Am Dent Assoc 1971;84:506-8.

9. Arra MC. A report of the dental program for migrants. J Wis Dent Assoc 1966;42:61-4.

10. Bagramian RA, Maggiore ED. An effective migrant oral health program using dental students as providers. J Mich Dent Assoc 1980;62:301-4.

11. Robinson E. The University of Michigan mobile dental program for migrant workers. J Mich Dent Assoc 1977;51:302-4.

12. Abrams WZ. Dentistry in migrant farm labor programs. J NJ Dent Assoc 1965;37:121-124.

13. Chapman A, Langworth RM. Dental services for migrants in Pennsylvania. Penn Dent 1969;36:241-3, 265.

14. Haas CO. Migrant summer dental health project. Dent Stud 1965;44:128-9.

15. Saunders L. Cultural difference and medical care: the case of the Spanish-speaking people of the Southwest. New York: Russell Sage Foundation, 1954

16. Bachand RG, Gangarosa LP, Bragassa C. A study of dental needs, DMF, def and tooth eruption in migrant negro children. J Dent Child 1971;38:399-402.

17. Avery KT. Dental health of migrant agricultural workers. J Occup Med 1974;16:606-8.

18. Slesinger DP, Cantley E. Medical utilization patterns of Hispanic migrant farmworkers in Wisconsin. Public Health Rep 1981;96:255-63.

19. Klein H, Palmer CE, Knutson JW. Studies on dental caries: I. Dental caries status and dental needs of elementary schoolchildren. Public Health Rep 1938;53:751-65.

20. Gruebbel, AD. A measurement of dental caries prevalence and treatment service for deciduous teeth. J Dent Res 1944;23:163-8.

21. Russell AL. A system of classification and scoring for prevalence surveys of periodontal disease. J Dent Res 1956;35:350-9.

22. Greene JC, Vermillion JR. The simplified oral hygiene index J Am Dent Assoc 1964;68:7-13.

23. Kelly JE, Harvey GR. Basic data on dental examinations of persons 1-74 years. United States 1971-1974. Hyattsville, Maryland: National Center for Health Statistics, 1974 DHEW publication no. (PHS) 79-1662 (Vital and health statistics; Series 11; no. 214).

24. National Caries Program, NIDR. The prevalence of dental caries in United States children, 1979-1980. NIH publication no. 82-2245, Dec 1981.

25. Brunelle JA, Carlos JP. Changes in the prevalence of dental caries in US schoolchildren, 1961-1980. J Dent Res 1982;61:1346-51.

26. Moore JW. Mexican Americans. Englewood Cliffs, NJ: Prentice-Hall, 1970 